\title{
Correlation of Fasting and Postprandial Glucose Levels with Glycosylated Hemoglobin in Diagnosis of Diabetes
}

\author{
Prija Poudyal,' Kabina Shrestha, ${ }^{1}$ Lily Rajbanshi, ${ }^{\prime}$ Afaque Anwar ${ }^{1}$ \\ 'Biratnagar Eye Hospital, Abhibadan marg, Rani, Biratnagar, Morang, Nepal.
}

\begin{abstract}
Introduction

Diabetes Mellitus describes a group of metabolic disorders characterized by hyperglycemia. Uncontrolled glycemic state often leads to micro and macro vascular complications. Diabetes is the foremost cause of new blindness in adults. Constant screening of the diabetic profile through blood tests of the affected people and prompt actions to control them can help to improve the quality of life of these patients. The study was done to evaluate the correlation between fasting and postprandial plasma glucose levels with glycosylated hemoglobin for diagnosis of diabetes and to determine the prevalence of diabetes in different age groups with sex predilection.
\end{abstract}

\section{Methods}

A descriptive cross sectional study was conducted and the data collection was carried out in the Department of Ophthalmic Pathology and Laboratory Medicine, Biratnagar Eye Hospital. Ethical approval was obtained from Institutional Review Committee of this hospital. All 275 patients who attended the laboratory from January 2019 to June 2019 for fasting plasma glucose, postprandial plasma glucose and glycosylated hemoglobin values estimation were included in this study. The data obtained were computed and analyzed using Statistical Package for the Social Sciences version 20.0

\section{Results}

A significant correlation between fasting plasma glucose, postprandial plasma glucose and glycosylated hemoglobin was observed in this study ( $p$ value $<0.001$ ). The correlation coefficient between fasting plasma glucose and glycosylated hemoglobin $(r=0.728)$ is stronger than the correlation coefficient between postprandial plasma glucose and glycosylated hemoglobin ( $\mathrm{r}=0.709)$.

\section{Conclusions}

Fasting plasma glucose correlated better than postprandial plasma glucose with glycosylated hemoglobin.

Keywords: diabetes mellitus; fasting plasma glucose; glycosylated hemoglobin; postprandial plasma glucose.

Correspondence: Dr. Prija Poudyal, Department of Ophthalmic Pathology and Laboratory Medicine, Biratnagar Eye Hospital, Biratnagar , Morang, Nepal. Email: kgktssbh@gmail.com, Phone : +977-9808200915. 


\section{INTRODUCTION}

Diabetes Mellitus describes a group of metabolic disorders characterized by increased blood glucose levels. It is due to the defect in the insulin release, its action or both and distubances of fat, carbohydrate and protein metabolism. ${ }^{1}$ The hyperglycemic state and the metabolic dysregulation result in complications affecting the kidneys, eyes, nerves and blood vessels. ${ }^{2}$ In the eyes, the uncontrolled diabetes may result in retinopathy, iridopathy, unstable refraction and cataract. $^{3}$ Early diagnosis and treatment can decrease the morbidity and mortality of the disease. Various laboratory blood tests like fasting plasma glucose, postprandial plasma glucose and glycosylated hemoglobin helps to diagnose and evaluate the diabetic status of the affected people. Hence, this study was done to determine the correlation between fasting and postprandial plasma glucose levels with glycosylated hemoglobin (HbA1c) in diagnosing diabetes mellitus and to find the prevalence of pre-diabetes and diabetes mellitus in different age groups with sex predilection.

\section{METHODS}

This descriptive cross sectional study was conducted in the Department of Ophthalmic Pathology and Laboratory Medicine, Biratnagar Eye Hospital. The Instituitional Review Committee of this hospital has approved the study. 275 patients who had undergone all the three tests (fasting plasma glucose, postprandial plasma glucose and glycosylated hemoglobin) from January 2019 to June 2019 were included in this study. The fasting plasma glucose test was done after 8-10 hours fast. The postprandial plasma glucose test was done after two hours post regular meal. The fasting and postprandial plasma glucose levels were estimated by enzymatic oxidation method
(GOD-PAP) using HumaStar 200 machine. $\mathrm{HbA1c}$ was measured by boronate conjugate assay using HumaMeter A1c machine. Patients aged 21 years and above who underwent all the three tests were included in the study. Any patient below 21 years or who didn't undertake any of the three tests was excluded from the study.

The patients were divided as according to their age groups into 21-35years, 36-50years, 51-65years, 66-80years and $>80$ years. These patients were also categorized into Normal, Pre diabetic and Diabetic using the variables of fasting plasma glucose, postprandial plasma glucose and $\mathrm{HbA1c}$ as determined by the American Diabetes Association (ADA). The ADA has established the criteria for diagnosis of diabetes, which states a fasting plasma glucose level of $>=126 \mathrm{mg} / \mathrm{dl}$, postprandial plasma glucose level of $>=200 \mathrm{mg} / \mathrm{dl}$ and $\mathrm{HbA} 1 \mathrm{c}$ of $>=6.5 \%$. Patients are termed pre diabetic if their fasting plasma glucose level is between 100$125 \mathrm{mg} / \mathrm{dl}$, postprandial plasma glucose level between $140-199 \mathrm{mg} / \mathrm{dl}$ and HbA1c $5.7-6.4 \%$. Patients with fasting plasma glucose $<100 \mathrm{mg} /$ $\mathrm{dl}$, postprandial plasma glucose $<140 \mathrm{mg} / \mathrm{dl}$ and $\mathrm{HbA} 1 \mathrm{c}<5.7 \%$ are non diabetics. ${ }^{4}$

In this study, the collected data was evaluated by linear regression test to investigate the correlation between fasting plasma glucose, postprandial plasma glucose and $\mathrm{HbA} 1 \mathrm{c}$ and t-test was used for comparison of $\mathrm{HbA} 1 \mathrm{c}$ with fasting and postprandial plasma glucose. The statistical analysis was done using SPSS 20.0

\section{RESULTS}

According to the fasting plasma levels, 54.5\% of the 21-35 years age group people fall into the diabetic range. In the age group 36-50 years, $20 \%$ are prediabetic and $45.3 \%$ are diabetic. The 51-65 years age group consists of $20.7 \%$ 
prediabetic and $34.0 \%$ diabetic people. The highest percentage of normal individuals was noted in the 66-80 years age group with $59.5 \%$. The oldest age group revealed equal percentage of prediabetic and diabetic patients (Figure 1).

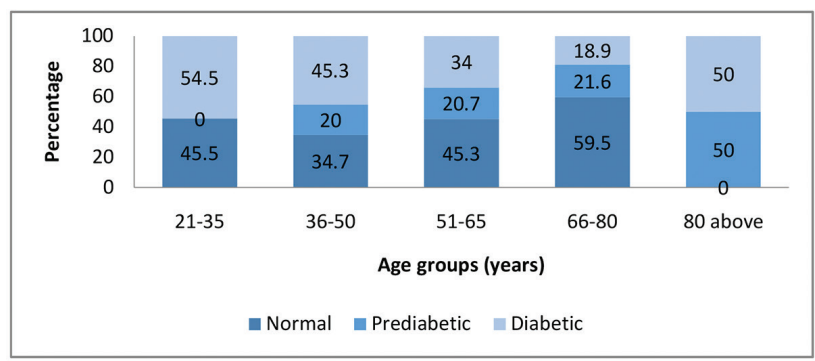

Figure 1. Age wise distribution of normal, pre-diabetic and diabetic people according to fasting plasma levels.

With reference to postprandial plasma glucose levels, $54.5 \%$ were diabetic in the youngest age group. The patients of 36-50 years age group were $30.7 \%$ prediabetic and $45.3 \%$ diabetic. The 51-65 years age group revealed increase in normal individuals $(36.7 \%)$ than prediabetic $(24.7 \%)$. The highest percentage of prediabetic (45.9\%) was recorded in 66-80 years age group. Patients 80 and above all had diabetes (Figure 2).

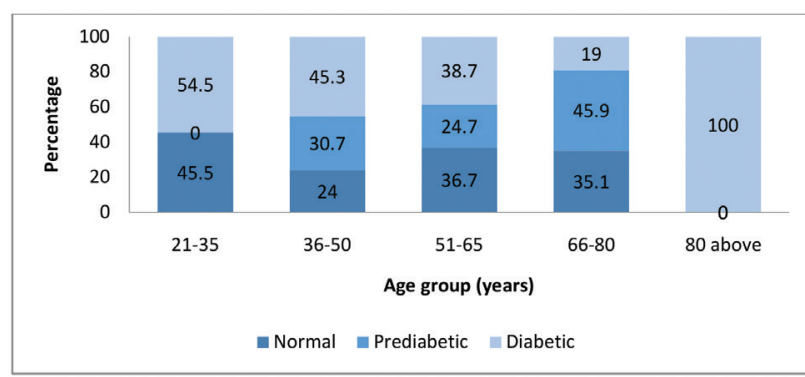

Figure 2. Age wise distribution of normal, prediabetic and diabetic people according to postprandial plasma levels.

Taking $\mathrm{HbA1c}$ as reference, $63.6 \%$ of patients of $21-35$ years age group and $81.3 \%$ of patients of 36-50 years age group were found to be diabetic. Highest percentage $(37.8 \%)$ of pre diabetics were found in 66-80 years age group. Patients 80 years and above were all diabetics (Figure 3).

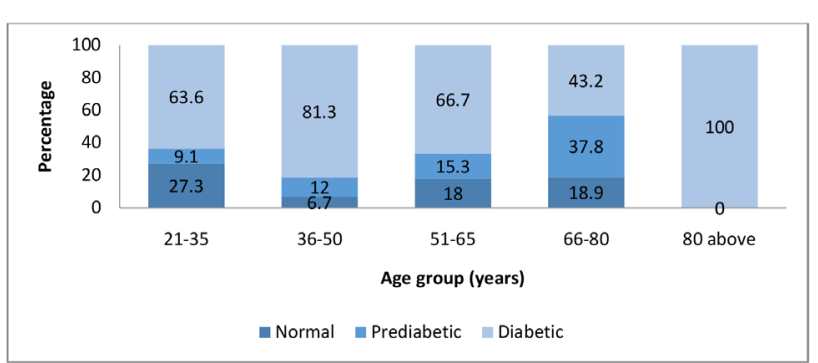

Figure 3. Age wise distribution of normal, prediabetic and diabetic people according to glycosylated hemoglobin

Highest numbers of patients were encountered in the 51-65 years age group. The mean values of $\mathrm{HbA1c}$ and fasting plasma glucose were recorded highest in the 21-35 age group patients. The postprandial plasma glucose revealed highest average values in patients of 80 years and above (Table1).

Table 1. Age wise distribution of glucose parameters.

\begin{tabular}{|c|c|c|c|c|}
\hline \multicolumn{2}{|c|}{ Age group (years) wise } & \multirow{2}{*}{$\frac{\text { Fasting }}{11}$} & \multirow{2}{*}{$\frac{P P}{11}$} & \multirow{2}{*}{$\frac{\mathrm{HbAlc}}{11}$} \\
\hline $21-35$ & Number of patients & & & \\
\hline & Mean & 140.36 & 211.45 & 8.57 \\
\hline & Standard Deviation & 69.638 & 114.056 & 3.411 \\
\hline \multirow[t]{3}{*}{$36-50$} & Number of patients & 75 & 75 & 75 \\
\hline & Mean & 136.16 & 206.03 & 8.30 \\
\hline & Standard Deviation & 59.705 & 81.102 & 2.020 \\
\hline \multirow[t]{3}{*}{$51-65$} & Number of patients & 150 & 150 & 150 \\
\hline & Mean & 121.50 & 186.50 & 7.83 \\
\hline & Standard Deviation & 57.403 & 86.212 & 2.242 \\
\hline \multirow[t]{3}{*}{$66-80$} & Number of patients & 37 & 37 & 37 \\
\hline & Mean & 100.11 & 170.57 & 6.89 \\
\hline & Standard Deviation & 34.333 & 69.882 & 1.790 \\
\hline \multirow{3}{*}{$\begin{array}{c}\text { More } \\
\text { than } 80\end{array}$} & Number of patients & 2 & 2 & 2 \\
\hline & Mean & 131.50 & 263.50 & 7.40 \\
\hline & Standard Deviation & 26.163 & 26.163 & 1.131 \\
\hline \multirow[t]{3}{*}{ Total } & Number of patients & 275 & 275 & 275 \\
\hline & Mean & 123.45 & 191.24 & 7.86 \\
\hline & Standard Deviation & 56.752 & 84.389 & 2.211 \\
\hline
\end{tabular}

The male population was more affected with pre diabetes and diabetes when fasting plasma glucose levels were analyzed (Figure 4). 


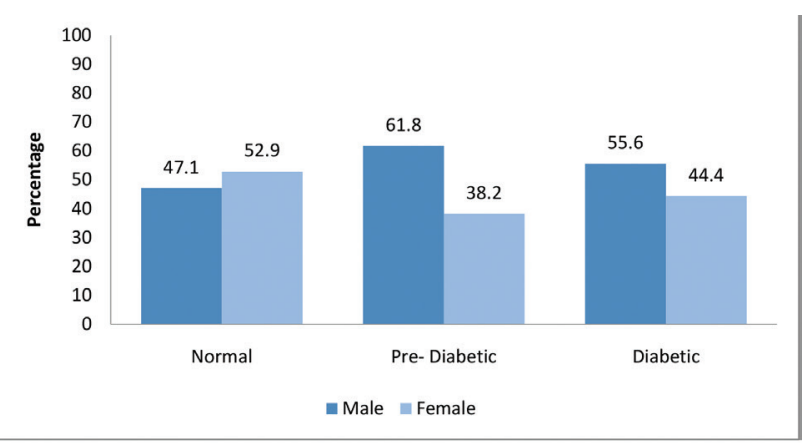

Figure 4. Gender distribution of normal, pre-diabetic and diabetic people according to fasting plasma levels.

The male population was more affected with pre diabetes and diabetes when postprandial plasma glucose levels were analyzed (Figure 5).

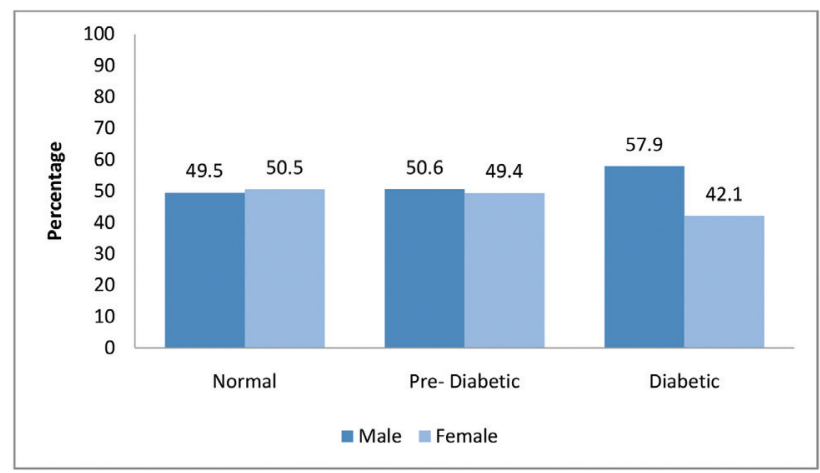

Figure 5. Gender distribution of normal, pre-diabetic and diabetic people according to postprandial plasma levels.

Females were found to be more pre diabetic and males more diabetic when $\mathrm{HbA} 1 \mathrm{c}$ test was done (Figure 6).

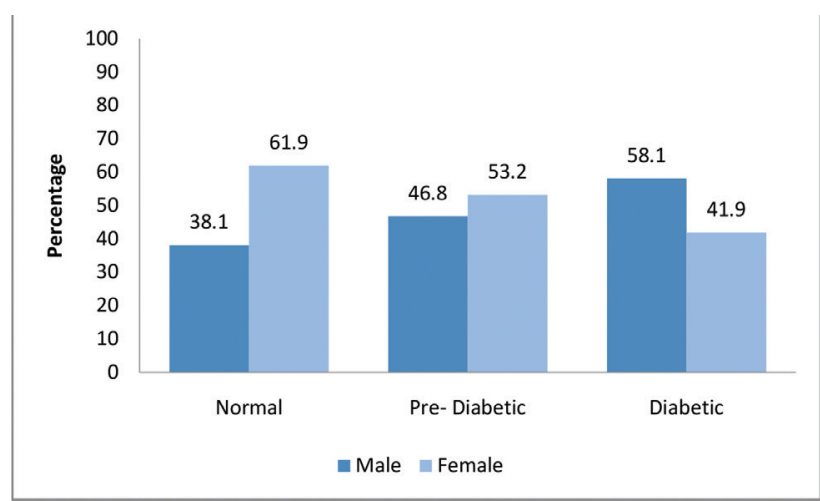

Figure 6. Gender distribution of normal, pre-diabetic and diabetic people according to $\mathrm{HbAlc}$.

The mean values of all three glucose parameters were higher in males compared to female population (Table 2).

Table 2. Gender wise distribution of glucose parameters.

\begin{tabular}{|l|l|l|l|l|}
\hline \multicolumn{2}{|c|}{ Gender wise } & Fasting & \multicolumn{1}{|c|}{ PP } & HbA 1 c \\
\hline \multirow{4}{*}{ Male } & Number of patients & 146 & 146 & 146 \\
& Mean & 126.89 & 197.70 & 8.15 \\
& Standard Deviation & 55.715 & 84.206 & 2.271 \\
\hline \multirow{2}{*}{ Female } & Number of patients & 129 & 129 & 129 \\
& Mean & 119.55 & 183.93 & 7.53 \\
& Standard Deviation & 57.873 & 84.324 & 2.101 \\
\hline \multirow{2}{*}{ Total } & Number of patients & 275 & 275 & 275 \\
\hline & Mean & 123.45 & 191.24 & 7.86 \\
& Standard Deviation & 56.752 & 84.389 & 2.211 \\
\hline
\end{tabular}

Taking both fasting and postprandial plasma glucose estimates into consideration, 121(44.0\%) patients are normal by fasting glucose levels, whereas 91 patients $(33.1 \%)$ are normal by postprandial glucose levels. More patients $(28.0 \%)$ were prediabetic by postprandial levels than fasting (20.0\%). Postprandial levels labeled 107 (38.9\%) patients as diabetic while fasting recorded $99(36.0 \%)$ patients as diabetic. However, 86 (31.3\%) patients were found to be diabetics when both fasting and postprandial levels were analyzed together. For those with normal fasting levels, 3.3\% had diabetes and $32.2 \%$ had prediabetes according to postprandial status (Table 3). A significant correlation was seen between the two parameters (Figure 7).

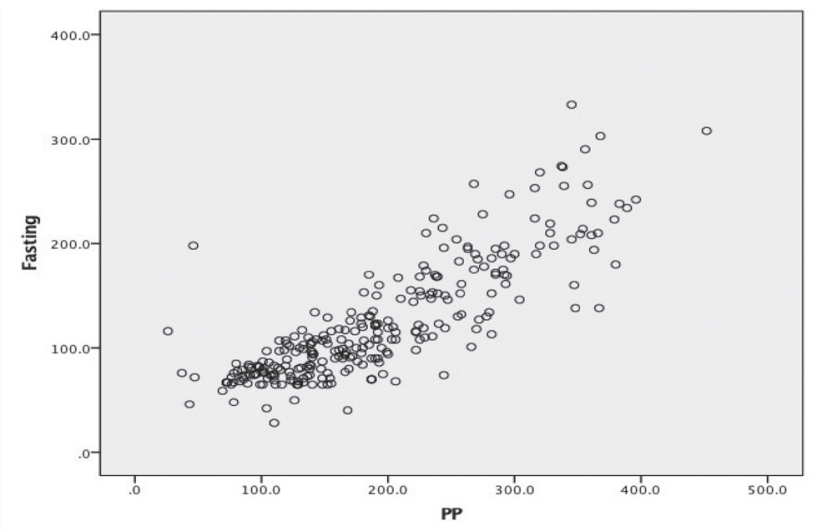

Figure 7. A scatter plot of fasting plasma glucose versus postprandial plasma glucose. 
Table 3. Fasting versus Postprandial glucose levels.

\begin{tabular}{|c|c|c|c|c|c|c|}
\hline & & & \multicolumn{3}{|c|}{ PP categorization } & \multirow[b]{2}{*}{ Total } \\
\hline & & & Normal & Pre diabetic & Diabetic & \\
\hline \multirow{9}{*}{$\begin{array}{c}\text { Fasting } \\
\text { Categorization }\end{array}$} & \multirow[t]{3}{*}{ Normal } & Count & 78 & 39 & 4 & 121 \\
\hline & & $\%$ within Fasting Categorization & $64.5 \%$ & $32.2 \%$ & $3.3 \%$ & $100.0 \%$ \\
\hline & & $\%$ of Total & $28.4 \%$ & $14.2 \%$ & $1.5 \%$ & $44.0 \%$ \\
\hline & \multirow[t]{3}{*}{ Prediabetic } & Count & 12 & 26 & 17 & 55 \\
\hline & & $\%$ within Fasting Categorization & $21.8 \%$ & $47.3 \%$ & $30.9 \%$ & $100.0 \%$ \\
\hline & & $\%$ of Total & $4.4 \%$ & $9.5 \%$ & $6.2 \%$ & $20.0 \%$ \\
\hline & \multirow[t]{3}{*}{ Diabetic } & Count & 1 & 12 & 86 & 99 \\
\hline & & $\%$ within Fasting Categorization & $1.0 \%$ & $12.1 \%$ & $86.9 \%$ & $100.0 \%$ \\
\hline & & $\%$ of Total & $.4 \%$ & $4.4 \%$ & $31.3 \%$ & $36.0 \%$ \\
\hline \multirow[t]{3}{*}{ Total } & & Count & 91 & 77 & 107 & 275 \\
\hline & $\begin{array}{l}\% \text { within Fasting } \\
\text { Categorization }\end{array}$ & $33.1 \%$ & $28.0 \%$ & $38.9 \%$ & $100.0 \%$ & \\
\hline & $\%$ of Total & $33.1 \%$ & $28.0 \%$ & $38.9 \%$ & $100.0 \%$ & \\
\hline
\end{tabular}

Taking both fasting and $\mathrm{HbA1c}$ estimates into consideration, $121(44.0 \%)$ patients were normal by fasting glucose levels, whereas 42 patients $(15.3 \%)$ were normal by HbA1c. More patients $(20.0 \%)$ were prediabetic by fasting levels than HbA1c (17.1\%). HbA1c labelled 186 (67.6\%) patients as diabetic while fasting recorded 99
(36.0\%) patients as diabetic. However, 94 (34.2\%) patients were found to be diabetics when both fasting and $\mathrm{HbA} 1 \mathrm{c}$ levels were analyzed together. For those with normal fasting levels, $24.8 \%$ had prediabetes and $41.3 \%$ had diabetes according to HbA1c status (Table 4). A significant correlation was seen between the two parameters (Figure 8).

Table 4. Fasting plasma glucose versus $\mathrm{HbAl}$ c.

\begin{tabular}{|c|c|c|c|c|c|c|}
\hline & & & \multicolumn{3}{|c|}{ HbA lc Categorization } & \multirow[b]{2}{*}{ Total } \\
\hline & & & Normal & Pre diabetic & Diabetic & \\
\hline \multirow{9}{*}{$\begin{array}{c}\text { Fasting } \\
\text { Categorization }\end{array}$} & \multirow[t]{3}{*}{ Normal } & Count & 41 & 30 & 50 & 121 \\
\hline & & $\%$ within Fasting Categorization & $33.9 \%$ & $24.8 \%$ & $41.3 \%$ & $100.0 \%$ \\
\hline & & $\%$ of Total & $14.9 \%$ & $10.9 \%$ & $18.2 \%$ & $44.0 \%$ \\
\hline & \multirow[t]{3}{*}{ Prediabetic } & Count & 1 & 12 & 42 & 55 \\
\hline & & $\%$ within Fasting Categorization & $1.8 \%$ & $21.8 \%$ & $76.4 \%$ & $100.0 \%$ \\
\hline & & $\%$ of Total & $.4 \%$ & $4.4 \%$ & $15.3 \%$ & $20.0 \%$ \\
\hline & \multirow[t]{3}{*}{ Diabetic } & Count & 0 & 5 & 94 & 99 \\
\hline & & $\%$ within Fasting Categorization & $0 \%$ & $5.1 \%$ & $94.9 \%$ & $100.0 \%$ \\
\hline & & $\%$ of Total & $0 \%$ & $1.8 \%$ & $34.2 \%$ & $36.0 \%$ \\
\hline \multirow[t]{3}{*}{ Total } & & Count & 42 & 47 & 186 & 275 \\
\hline & $\begin{array}{l}\% \text { within Fasting } \\
\text { Categorization }\end{array}$ & $15.3 \%$ & $17.1 \%$ & $67.6 \%$ & $100.0 \%$ & \\
\hline & $\%$ of Total & $15.3 \%$ & $17.1 \%$ & $67.6 \%$ & $100.0 \%$ & \\
\hline
\end{tabular}




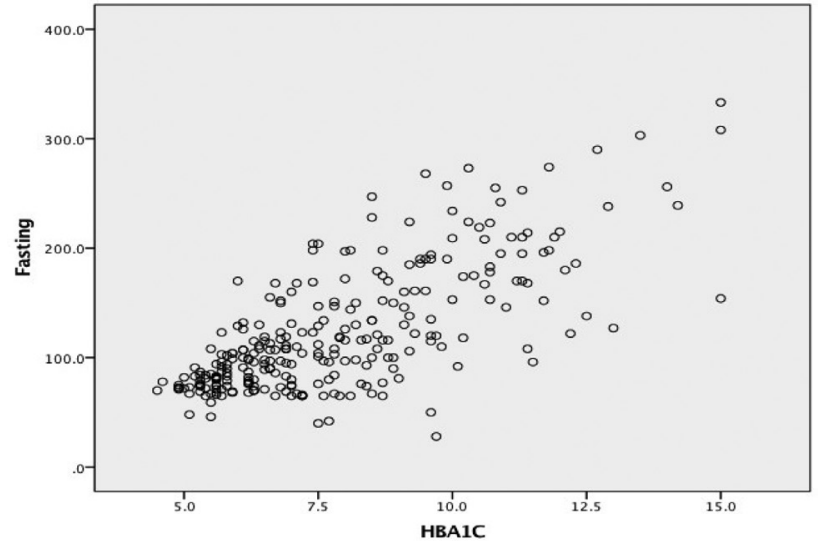

Figure 8. A scatter plot of fasting plasma glucose versus HbAlc.

Taking both postprandial and $\mathrm{HbA1c}$ estimates into consideration, 91(33.1\%) patients were normal by postprandial glucose levels, whereas 42 patients $(15.3 \%)$ were normal by $\mathrm{HbA1c}$. More patients (28.0\%) were prediabetic by postprandial levels than HbA1c (17.1\%). HbA1c labelled 186 (67.6\%) patients as diabetic while postprandial recorded 107 (38.9\%) patients as diabetic. However, 101 (36.7\%) patients were found to be diabetics when both postprandial and $\mathrm{HbA1c}$ levels were analyzed together. For those with normal postprandial levels, $40.4 \%$ had prediabetes and $18.8 \%$ had diabetes according to $\mathrm{HbA1c}$ status (Table 5). A significant correlation was seen between the two parameters (Figure 9).

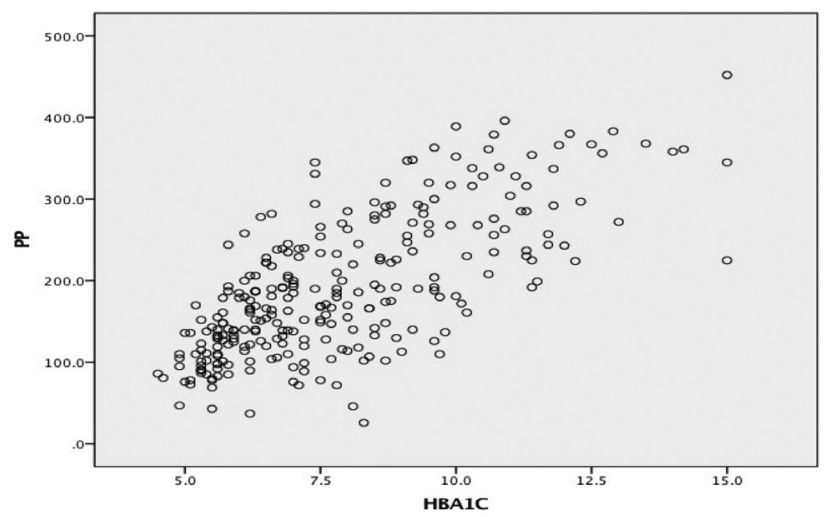

Figure 9. A scatter plot of postprandial plasma glucose versus HbAlc.

Table 5. HbAlc versus Postprandial plasma glucose.

\begin{tabular}{|c|c|c|c|c|c|c|}
\hline & & & \multicolumn{3}{|c|}{ PP categorization } & \multirow[b]{2}{*}{ Total } \\
\hline & & & Normal & Prediabetic & Diabetic & \\
\hline \multirow{9}{*}{$\begin{array}{c}\mathrm{HbAlc} \\
\text { Categorization }\end{array}$} & \multirow[t]{3}{*}{ Normal } & Count & 37 & 5 & 0 & 42 \\
\hline & & $\%$ within HBAlc Categorization & $88.1 \%$ & $11.9 \%$ & $0 \%$ & $100.0 \%$ \\
\hline & & $\%$ of Total & $13.5 \%$ & $1.8 \%$ & $0 \%$ & $15.3 \%$ \\
\hline & \multirow[t]{3}{*}{ Prediabetic } & Count & 19 & 22 & 6 & 47 \\
\hline & & $\%$ within $\mathrm{HBA} 1 \mathrm{c}$ Categorization & $40.4 \%$ & $46.8 \%$ & $12.8 \%$ & $100.0 \%$ \\
\hline & & $\%$ of Total & $6.9 \%$ & $8.0 \%$ & $2.2 \%$ & $17.1 \%$ \\
\hline & \multirow[t]{3}{*}{ Diabetic } & Count & 35 & 50 & 101 & 186 \\
\hline & & $\%$ within $\mathrm{HBA}$ lc Categorization & $18.8 \%$ & $26.9 \%$ & $54.3 \%$ & $100.0 \%$ \\
\hline & & $\%$ of Total & $12.7 \%$ & $18.2 \%$ & $36.7 \%$ & $67.6 \%$ \\
\hline \multirow[t]{3}{*}{ Total } & & Count & 91 & 77 & 107 & 275 \\
\hline & $\begin{array}{l}\% \text { within HBAlc } \\
\text { Categorization }\end{array}$ & $33.1 \%$ & $28.0 \%$ & $38.9 \%$ & $100.0 \%$ & \\
\hline & $\%$ of Total & $33.1 \%$ & $28.0 \%$ & $38.9 \%$ & $100.0 \%$ & \\
\hline
\end{tabular}


Thecorrelation coefficientbetweenfastingplasma glucose and $\mathrm{HbA1c}(\mathrm{r}=0.728)$ is stronger than the correlation coefficient between postprandial plasma glucose and HbA1c (r=0.709) using Pearson's correlation coefficient. The $p$ value between the three glucose parameters was estimated. A significant correlation was noted between them ( $p$ value $<0.001$ ) (Table 6).

\begin{tabular}{|c|c|c|c|c|}
\hline \multicolumn{5}{|c|}{$\begin{array}{l}\text { Table 6. Correlation between fasting plasma glucose, } \\
\text { postprandial plasma glucose and glycosylated } \\
\text { hemoglobin. }\end{array}$} \\
\hline & & Fasting & PP & $\mathrm{HbAlc}$ \\
\hline \multirow[t]{2}{*}{ Fasting } & Pearson Correlation & 1 & $.840^{* *}$ & $.728^{* *}$ \\
\hline & Sig. (2-tailed) & & .000 & .000 \\
\hline \multirow[t]{2}{*}{ PP } & Pearson Correlation & $.840^{* *}$ & 1 & $.709^{* *}$ \\
\hline & Sig. (2-tailed) & .000 & & .000 \\
\hline \multirow[t]{2}{*}{$\mathrm{HbAlc}$} & Pearson Correlation & $.728^{* *}$ & $.709^{* *}$ & 1 \\
\hline & Sig. (2-tailed) & .000 & .000 & \\
\hline
\end{tabular}

\section{DISCUSSION}

Glycosylated hemoglobin (HbA1c) is a form of hemoglobin which is chemically linked to a sugar molecule. Most monosaccharides like glucose non-enzymatically bond with hemoglobin $(\mathrm{Hb})$ when present in the blood stream of the humans. The rate of formation of glucose bound $\mathrm{Hb}$ (glycated hemoglobin) is directly proportional to the amount of glucose present in the body at that time. $\mathrm{HbA} 1 \mathrm{c}$ reflects an average blood glucose level of 2-3 months, as the red blood cells remain in circulation for maximum of 120 days. It can be used as a diagnostic test for diabetes mellitus and as assessment test for monitoring glycemic control in diabetes people. In this study, considering $\mathrm{HbA} 1 \mathrm{c}$ as the parameter, the prevalence of diabetes are $63.6 \%$ and $81.3 \%$ in 21-35 years and 36-50 years age groups respectively. Among 66-80 years age group,
$37.8 \%$ are prediabetics and $43.2 \%$ are diabetics. According to a study in Nepal, diabetes was present in $14.6 \%$ of people $\geq 20$ years old in urban and $2.5 \%$ in rural areas. Among those $>40$ years old, diabetes was present in $18.3 \%$ in urban and $3.3 \%$ in rural areas. ${ }^{5}$ Studies by Nitesh K K et al., ${ }^{6}$ reported the prevalence of diabetes were $16.22 \%$ in $30-40$ years age group, $24.32 \%$ in $41-50$ years age group, $43.34 \%$ in 51-60 years age group and $16.2 \%$ in $61-70$ years age group respectively. This study also revealed the mean average of $\mathrm{HbA} 1 \mathrm{c}$ and fasting plasma glucose levels are higher in younger generation compared to the elderly ones. It is noted that most elderly people diagnosed with diabetes are under medications and close follow up maintaining the glycemic status. But the younger generations are unaware of their diabetic status, as no screening has been done, with the existing misconception that diabetes is the disease of the old. With increasing urbanization, food habits, sedentary life style, the rate of prevalence of diabetes in younger people has been increasing worldwide. In USA and UK, type 2 DM have affected people less than 19 years. In Japan, 50-75\% of people aged 10-29 years have type $2 \mathrm{DM}^{7}$ Development of type 2 $\mathrm{DM}$ at young age leads to early exposure to the harmful effects of hyperglycemia and vascular complications. Life expectancy is reduced by eight years if type $2 \mathrm{DM}$ is diagnosed in a person at age $40 .{ }^{8}$ As a result, our future generations may have to tolerate the morbidity and mortality of the disease at the peak of their productive years. This will in-turn affect the health care systems and economy of the countries across the world. This study also revealed that the mean average of postprandial plasma levels is higher in elderly patients. This is in concordance with the study by Lim et al., ${ }^{9}$ which hypothesized that it might be because of increased beta cell insufficiency in elder generation. The presence of hypoglycemia thus may have lead to defensive eating and 
overcorrection of hypoglycemia finally resulting in postprandial hyperglycemia This study also concluded male population being more affected by diabetes than female. Similar findings have been reported by other studies. ${ }^{6,10-11}$

In our study, $44 \%$ and $33.1 \%$ of the total cases were termed normal under fasting and postprandial criteria respectively but only $15.3 \%$ were found non diabetic using $\mathrm{HbA1c}$ based criteria. For those with normal fasting levels, $24.8 \%$ had prediabetes and $41.3 \%$ had diabetes according to $\mathrm{HbA1c}$ status. Also, for those with normal postprandial levels, $40.4 \%$ had prediabetes and $18.8 \%$ had diabetes according to $\mathrm{HbA} 1 \mathrm{c}$ status. This discordant result may be because of short term and momentarily alterations in dietary habits, fasting, exercise or use of medications. These methods happen to decrease the plasma glucose levels in a short period of time but not HbA1c. This shows there is a high chance of poor glycemic control in the patients included in this study. This also may indicate that these patients may have prepared themselves only for the hospital visiting days. ${ }^{12}$ Our study also concluded that $17.1 \%$ and $67.6 \%$ of the total cases were prediabetics and diabetics using HbA1c which supports the conclusion that $\mathrm{HbA1c}$ identified more people at risk compared to plasma levels as reported in other studies. ${ }^{13-16}$

$\mathrm{HbA1c}$ and plasma glucose provide different information and have varied advantages and disadvantages. The plasma glucose levels indicate the blood glucose at that given moment, is relatively convenient and cheap. But a single reading of plasma glucose may be affected due to stress, alcohol, dehydration and steroids. ${ }^{17-18}$ On the other hand, $\mathrm{HbA} 1 \mathrm{c}$ is a better indicator of glycemic exposure, provides average plasma values of 8-12 weeks and is a reliable index for estimation of longterm complications. It doesn't require fasting or timed samples or any preparations. It has a less biological variability and less preanalytical instability. ${ }^{19}$ But it may be influenced by conditions like red cell turnover, hemoglobin subtype, hypertriglyceridemia, chronic alcoholic status and ethnicity irrespective of glucose concentration levels. ${ }^{20-21}$

If clinically unsure, it is advised to repeat the same test immediately with new blood sample for confirmation. If two different tests results are above the diagnostic levels, diabetes is confirmed. But, if discordant results are obtained, the test whose result is above the diagnostic threshold should be repeated again and final diagnosis should be made on basis of the results of the repeated confirmatory test. Also due to the preanalytic and analytic variablility of the different tests, a test whose result was above the diagnostic cut point when repeated can yield result below the diagnostic cut point. This happens most likely in 2 hour postprandial estimation, more likely in fasting values and least likely in $\mathrm{HbA} 1 \mathrm{c} .{ }^{21}$

After the ADA 2010 recommendation, there has been a gradual increase in using $\mathrm{HbA} 1 \mathrm{c}$ as a diagnostic test for diabetes mellitus and has been considered a reliable biomarker in diagnosis and prognosis of diabetes. ${ }^{22} \mathrm{HbA} 1 \mathrm{c}$ test is widely used and accepted as the means of retrospectively analyzing the mean glycemic status. But in developing countries like Nepal, where majority of the population is below the poverty line, HbA1c may be expensive for them. Also the test may be unavailable or still not properly standardized in these places. So, the idea of correlation of fasting and postprandial plasma glucose with $\mathrm{HbA1c}$ may be helpful in keeping the glycemic value under control. As a result, various research studies have been ongoing to determine the relative contribution of fasting and postprandial glucose levels as well. In this regard, our study revealed fasting 
and postprandial glucose levels are significantly correlated with glycosylated hemoglobin $(p<0.001)$. However, fasting glucose level has a stronger correlation coefficient $(r=0.728)$ than postprandial glucose level (0.709). These findings are in accordance to findings of Saiedullah et al., ${ }^{23}$ and Gupta S et al., ${ }^{24}$ On the other hand, Rosediani et al., ${ }^{25}$ Shrestha et al., ${ }^{26}$ and Swetha et al., ${ }^{27}$ have concluded that postprandial glucose levels correlated better with glycosylated hemoglobin in comparison to fasting glucose levels.

\section{CONCLUSIONS}

This study shows that the prevalence of diabetes mellitus is exponentially increasing in the young generation. People with risk factors and family history should screen their diabetic profile and those with the disease should regularly monitor their glycemic status. In this study, though both fasting and postprandial plasma glucose levels correlated significantly with

\section{REFERENCES}

1. World Health Organization. Classification of diabetes mellitus. $2019 . \quad$ https://apps.who.int/iris/ handle/10665/325182.

2. Kumar V, Abbas AK, Aster JC, Perkins JA. Robbins and Cotran pathologic basis of disease. 9th Edition. Philadelphia: Elsevier; 2015. p. 1105.

3. Kanski JJ. Clinical Ophthalmology: A systematic approach. 6th Edition. Edinburg: Butterworth-Heinemann/ Elsevier; 2007. p. 909.

4. American Diabetes Association. Diagnosis and classification of diabetes mellitus. Diabetes Care 2010;33(Suppl glycosylated hemoglobin, the former showed better correlation with $\mathrm{HbA} 1 \mathrm{c}$ than the latter.

\section{LIMITATIONS}

Glycosylated hemoglobin varies in conditions of anaemia, hemoglobinopathies, alcoholism, chronic renal failure, hyperbilirubinaemia, hypertriglyceridemia, spleenectomy which are not taken in consideration in our study. The present study was carried out in a small sample size. HbA1c and plasma glucose tests were carried on a single day. However, several glucose readings over a period of several weeks can be better correlated to $\mathrm{HbA} 1 \mathrm{c}$ than a single glucose reading on a single day.

\section{ACKNOWLWDGEMENTS}

The authors would like to express gratitude to the laboratory staffs of Biratnagar Eye Hospital for their help and support to conduct the study.

\section{Conflict of Interest: None.}

\section{1):S62-S69. https://doi.org/10.2337/ dc10-S062}

5. Singh DL, Bhattarai MD. High prevalence of diabetes and impaired fasting glycemia in urban Nepal. Diabetes UK. Diabetic Medicine. 2003; 20(2):170-171. https://doi.org/10.1046/ j.1464-5491.2003.00829_4.x

6. Kumar KN, Katkuri S, Ramyacharitha I. A study to assess prevalence of diabetes mellitus and its associated risk factors among adult residents of rural Khammam. International Journal of Community Medicine and Public Health. 2018; 5:1360. doi: 10.18203/23946040.ijcmph20180985

7. Htike ZZ, Webb D, Khunti K, Davies 
M. Emerging epidemic and challenges of Type 2 diabetes in young adults. Diabetes Manag. 2015;5(6):473-483. doi:10.2217/ dmt.15.39

8. $\quad$ Roper NA, Bilous RW, Kelly WF, Unwin NC, Connolly VM. Excess mortality in a population with diabetes and the impact of material deprivation: longitudinal, population based study. BMJ. 2001;322(7299):1389-1393. doi:10.1136/ bmj.322.7299.1389

9. Lim LL, Brnabic AJ, Chan SP, Ibrahim L, Paramasivam SS, Ratnasingam J, et al. Relationship of glycated hemoglobin, and fasting and postprandial hyperglycemia in type 2 diabetes mellitus patients in Malaysia. Journal of diabetes investigation. 2017; 8(4):453461. https://doi.org/10.1111/jdi.12596

10. Chen GY, Li L, Dai F, Li XJ, Xu XX, Fan JG, et al. Prevalence of and risk factors for type 2 diabetes mellitus in hyperlipidemia in China. Med Sci Monit. 2015; 21:247684. doi:10.12659/ MSM.894246

11. Amarasinghe $S$, Balakumar $S$, Arasaratnam V. Prevalence and risk factors of diabetes mellitus among adults in Jaffna District. Ceylon Med J. 2015;60 (3):107110. doi:10.4038/cmj.v60i3.8191

12. Akinloye $\mathrm{O}$, Adaramoye OA, Akinlade KS, Odetola AA, Raji, AA. Relationship between Fasting Plasma Glucose and Glycated Haemoglobin In Adult Diabetic Nigerians. African Journal of Biomedical Research. 2010; 10. doi: 10.4314/ajbr. v10i2.50614

13. Zhang $\mathrm{YH}, \mathrm{Ma}$ WJ, Thomas GN, Xu YJ, Lao XQ, Xu XJ, et al. Diabetes and pre- diabetes as determined by glycated haemoglobin A1c and glucose levels in a developing southern Chinese population. PloS one. 2012; 7(5): e37260. https://doi.org/10.1371/journal. pone.0037260

14. Jeon JY, Ko SH, Kwon HS, Kim NH, Kim JH, Kim CS, et al; Taskforce Team of Diabetes Fact Sheet of the Korean Diabetes Association. Prevalence of Diabetes and Prediabetes according to Fasting Plasma Glucose and HbA1c. Diabetes \& metabolism journal. 2013; 37(5):349-357. https://doi. org/10.4093/dmj.2013.37.5.349

15. Ho-Pham LT, Nguyen UDT, Tran TX, Nguyen TV. Discordance in the diagnosis of diabetes: Comparison between $\mathrm{HbA1c}$ and fasting plasma glucose. PLoS One. 2017;12(8):e0182192. doi:10.1371/journal.pone.0182192

16. Perry RC, Shankar RR, Fineberg N, McGill J, Baron AD; Early Diabetes Intervention Program (EDIP). HbA1c measurement improves the detection of type 2 diabetes in high-risk individuals with nondiagnostic levels of fasting plasma glucose: the Early Diabetes Intervention Program (EDIP). Diabetes care. 2001;24(3):465-471. doi:10.2337/ diacare.24.3.465

17. Good to know: factors affecting blood glucose. Clinical diabetes: a publication of the American Diabetes Association. 2018;36(2):202. doi: 10.2337/cd18-0012

18. Malkani S, Mordes JP. Implications of using hemoglobin A1C for diagnosing diabetes mellitus. The American journal of medicine. 2011;124(5): 
395-401. https://doi.org/10.1016/j. amjmed.2010.11.025

19. Mahajan, RD, Mishra, B. Using glycated hemoglobin $\mathrm{HbA1c}$ for diagnosis of diabetes mellitus: an Indian perspective. Int J Bio Med Res. 2011; 2(2):508-512

20. Bennett CM, Guo M, Dharmage SC. $\mathrm{HbA1c}$ as a screening tool for detection of Type 2 diabetes: a systematic review. Diabet Med 2007; 24(4):333-43. doi:10.1111/j.1464-5491.2007.02106.x

21. American Diabetes Association. Classification and diagnosis of diabetes. Diabetes Care. 2015; 38 (Suppl 1): S8S16. https://doi.org/10.2337/dc15-S005

22. Sherwani SI, Khan HA, Ekhzaimy A, Masood A, Sakharkar MK. Significance ofHbA1cTestinDiagnosisand Prognosis of Diabetic Patients. Biomarker insights. 2016;11:95-104. https://doi.org/10.4137/ BMI.S38440

23. Saiedullah M, Hayat S, Kamaluddin SM, Begum S. Correlation of Fasting and Post Prandial Plasma Glucose with Hemoglobin Glycation. AKMMC J. 2013;4(2):28-30. doi: 10.3329/akmmcj. v4i2.16939

24. Gupta S, Puppalwar PV, Chalak A. Correlation of fasting and postmeal plasma glucose level to increased HbA1c levels in type-2 diabetes mellitus. Int J Adv Med. 2014;1:127-31. doi: 10.5455/2349-3933.ijam20140824
25. Rosediani M, Azidah AK, Mafauzy M. Correlation between fasting plasma glucose, post prandial glucose and glycated haemoglobin and fructosamine. Med J Malaysia. 2006;61(1):67-71.

26. Shrestha L, Jha B, Yadav B, Sharma S. Correlation between fasting blood glucose, postprandial blood glucose and glycated hemoglobin in non insulin treated type 2 diabetic subjects. Sunsari Technical College Journal. 2012;1(1):18-21. https://doi.org/10.3126/ stcj.v1i1.8654

27. Swetha NK. Comparison of fasting blood glucose \& post prandial blood glucose with $\mathrm{HbA1c}$ in assessing the glycemic control. International $\mathrm{J}$ of Healthcare and Biomedical Research. 2014; 2(3):134-139.

28. Kam-On Chung J, Xue H, Wing-Hang Pang E, Chuen-Chu Tam D. Accuracy of fasting plasma glucose and hemoglobin A1c testing for the early detection of diabetes: a pilot study. Front Lab Med. 2017;1:76-81. doi: http://dx.doi. org/10.1016/j.flm.2017.06.002

29. International Expert Committee. International Expert Committee report on the role of the A1c assay in the diagnosis of diabetes. J Diabet Care. 2009;32:1327-1334. doi:10.2337/dc099033

Citation: Poudyal P, Shrestha K, Rajbanshi L, Anwar A. Correlation of Fasting and Postprandial Glucose Levels with Glycosylated Hemoglobin in Diagnosis of Diabetes. JCMS Nepal. 2021 ; 17(1); 44-54. 